\title{
Narratives in Cypriot Greek mono- and bilingual children with SLI
}

Eleni Theodorou, Kleanthes K. Grohmann

Department of English Studies, University of Cyprus, Cyprus

https://doi.org/10.36505/ExLing-2010/03/0047/000167

\begin{abstract}
Narrative ability is one of the most promising ways to assess communicative competence in children: Coordination of lexical, morphosyntactic, phonological, and pragmatic elements is needed to produce narrations. Narratives might even serve as a diagnostic tool for Specific Language Impairment, since children with Specific Language Impairment are reported to have difficulties producing (oral) narratives. Different approaches are available for narrative analysis. In the present study, the Renfrew Bus Story Test was used to investigate narrative ability in mono- and bilingual children aged between 5 and 10 years with typical and impaired language development acquiring Cypriot Greek. The findings suggest that narratives can indeed be a useful tool to identify and assess language-impaired children.
\end{abstract}

Key words: Cypriot Greek, mono- and bilingual first language acquisition, narrative ability, Renfrew Bus Story Test, Specific Language Impairment

\section{Introduction}

It is well known among linguists and clinicians that coordination of language and a cognitive ability is essential to comprehend and produce narrations. All aspects of language (e.g. lexicon, morphosyntax, phonology, pragmatics) and high function abilities such as attention, processing, and memory need to be coordinated in order to tell an adequate and a tangible story.

Narratives are found across different contexts, cultures, and times, conveying significant information. Narratives form the bases of social interactions contributing to individuals' self-concept (McCabe 1996). It was described by Labov and Waletzky (1967) as the temporal organization and sequencing of past experience into a linguistic device available to speakers. A large body of literature exists which describes the oral narrative skills of young children with typical language development as well as children with language impairment, including Specific Language Impairment (SLI), across different languages. However, there are no such studies on Cypriot Greek, neither with typically developing (TD) mono- or bilingual children nor with impaired children of any kind, in particular SLI.

Justice et al. (2009) suggest that analysis of children's oral narratives represents an informative approach to language assessment. The development of oral narrative is an important achievement, while storytelling plays a significant and critical role in

ExLing 2010: Proceedings of 3rd Tutorial and Research Workshop on Experimental Linguistics, 25-27 August, Athens, Greece 
academic success. The relationship between academic success and narrative ability has been further amplified by data demonstrating that children with literacy difficulties show persistent difficulties over time in narrative production (Feagans and Short 1984).

SLI is a term applied to children who exhibit a significant deficit in language ability yet display normal hearing, age-appropriate scores on tests of non-verbal intelligence, and no obvious signs of neurological damage. SLI causes difficulties in one or more aspects of language: word finding, phonology, morphology, syntax, semantics, and pragmatics (Leonard 1998), which is why SLI is characterized by lack of homogeneity. SLI has been estimated to affect approximately $7 \%$ of children, with boys more affected than girls (Tomblin et al. 1997).

Regarding the relation between SLI and narrative ability, previous research, especially in the area of language pathology, shows that children with SLI retell and produce narratives that are less competent and immature with respect to length, lexical diversity, sentence complexity, and content (Gillam and Pearson 2004). Moreover, details that make the story more complete, such as cohesive devices or markers are missing in children with SLI (Leonard 1998). Narrative ability is considered a strong predicting factor for academic success for children with SLI since proficiency in storytelling contributes toward academic performance (Crais \& Lorch 1994, Bishop and Edmundson 1987), particularly the acquisition of literacy (Paul et al. 1996). Another important indication for the relation between narratives and SLI refers narrative skill as an area of oral language in which delay is less likely to resolve over time (Girolametto et al. 2001).

With regard to the analysis of narratives, researchers have differentiated between micro- and macro-structural analyses (Hughes, McGillivray, and Schmidek 1997): Micro-structures concern semantic and syntactic complexity of narratives, while macro-structures focus on coherence and organization of the narrative.

Current practice in the field of speech therapy employs narratives in assessment.

\section{Method \\ Participants}

In the present study, the Renfrew Bus Story Test (BST) was used to investigate narrative ability in three groups of children. Ten monolingual children with SLI acquiring Cypriot Greek (aged 5;3-9;3), 4 bilingual children with SLI with Cypriot Greek as one of the two languages $(7 ; 6-9 ; 3)$, and, as the control group, 12 monolingual TD children acquiring Cypriot Greek $(5 ; 4-9 ; 11)$ participated in the study. TD children were recruited randomly from public pre-primary schools in Limassol; children with SLI 
were recruited from speech and language therapists in public and in private settings, both upon written parental consent. Participants were assessed on a large testing battery, including the Developmental Verbal IQ Test, the Peabody Picture Vocabulary Test, and the Phonological Phonetic Test, among others. Children showed no evidence of hearing loss, obvious neurological lesion, social problems, or psychiatric syndromes, and they had a non-verbal IQ score higher than 80 measured by the Raven Coloured Progressive Matrices.

\section{Procedures}

The BST is a screening test of verbal expression that examines story retelling with picture support. It can demonstrate difficulties with verbal expression, as well as phonological, semantic, grammatical, and sequencing problems. The experimenter told each child a short story about a red bus, while the child looked through a book of pictures illustrating the story. The child then retold it, using the pictures as prompts. The narrations were recorded, transcribed, and evaluated with respect to three measures the BST suggests: the amount of original information included (Inf. Total in Table 1 below), the number of subordinate clauses (Sub. Cl.) and the mean sentence length of the longest five sentences (A5LS).

\section{Results}

The table below displays the mean scores for the three measures that were evaluated. The scores in all three measures are found to be different between the two experimental groups (moSLI and biSLI) and the control group (TD).

\begin{tabular}{|llll}
\hline \hline & TD $(\mathrm{n}=12)$ & moSLI $(\mathrm{n}=10)$ & biSLI $(\mathrm{n}=4)$ \\
Mean Age & $6 ; 4 \mathrm{y}$ & $6 ; 3 \mathrm{y}$ & $8 ; 8 \mathrm{y}$ \\
Inf. Total (mean) & 33.4 & 24.1 & 25.5 \\
Sub. Cl. (mean) & 4.7 & 2.0 & 2.25 \\
A5LS (mean) & 9.2 & 5.9 & 7.15 \\
\hline \hline
\end{tabular}

Looking through the mean scores, monolingual and bilingual children with SLI (moSLI and biSLI, respectively) performed worse in all three measures than the TD children did in Cypriot Greek. Looking into individual scores, which are not displayed here for space reasons, differences among individuals in the same group are noticed. However, these differences cannot underestimate the lower score of SLI children, mono- and bilingual. 


\section{Discussion}

This study confirmed previous research findings regarding narrative ability in mono- and bilingual children with SLI concerning use of complex syntax and mean length of utterances. Our preliminary findings indicate that the BST and narrative assessment can generally provide clinicians with enough information regarding language skills. In addition, information such as narrative abilities may be useful for assessing and monitoring language development within the language intervention program.

\section{References}

Bishop, D.V.M., Edmundson, A. 1987. Language-impaired four year olds: Distinguishing transient from persistent impairment. Journal of Speech and Hearing Disorders, 52, 156-173.

Crais, E., Lorch, N. 1994. Oral narratives in school aged children. Topics in Language Disorders, 14, 13-28.

Dunn, L., Dunn, L. 1981. Peabody Picture Vocabulary Test. Circle Pines, MN, American Guidance Service.

Feagans, L., Short, E.J. 1984. Developmental differences in the comprehension and production of narratives by reading disables and normally achieving children. Child Development. 55, 1727-1736.

Gillam, R.B., Pearson, N. 2004. Test of narrative language. Austin, TX: Pro-Ed.

Girolametto, L., Wiigs, M., Smyth, R., Weitzman, E., Pearce, P.S. 2001. Children with a history of expressive language delay: Outcomes at 5 years of age. American Journal of Speech-Language Pathology, 10, 358-369.

Hughes, D., McGillivray, L., Schmidek, M. 1997. Guide to narrative language procedures for assessment. Eau Claire, WI, Thinking Publications.

Justice, L.M., Bowles, R.P., Kaderavek, J.N., Ukrainetz, T.A., Eisenberg, S.L., Gillam, R.B. 2006. The index of narrative microstructure: A clinical tool for analysing school-age children's narrative performances. American Journal of Speech and Language Pathology, 15, 155-191.

Leonard, L. 1998. Children with Specific Language Impairment. Cambridge, MA, MIT Press.

McCabe, A. 1996. Chameleon readers: Teaching children to appreciate all kinds of good stories. New York, NY, McGraw-Hill.

Paul, R., Hernandez, R., Taylor, L., Johnson, K. 1996. Narrative development in late talkers: early school age. Journal of Speech and Hearing Research 39, 1295-1303.

Tomblin, J., Records, N., Buckwalter, P., Zhang, X., Smith, E., O’Brien, M. 1997. Prevalence of specific language impairment in kindergarten children. Journal of Speech, Language and Hearing research, 40, 1245-60. 